\title{
Carotenoid intakes, assessed by food-frequency questionnaires (FFQs), are associated with serum carotenoid concentrations in the Jackson Heart Study: validation of the Jackson Heart Study Delta NIRI Adult FFQs
}

\author{
Sameera A Talegawkar ${ }^{1}$, Elizabeth J Johnson ${ }^{1}$, Teresa C Carithers ${ }^{2}$, Herman A Taylor Jr ${ }^{3}$, \\ Margaret L Bogle ${ }^{4}$ and Katherine L Tucker ${ }^{1, *}$ \\ 'Jean Mayer USDA Human Nutrition Research Center on Aging at Tufts University, 711 Washington Street, \\ Boston, MA 021 11 , USA: ${ }^{2}$ Department of Family and Consumer Sciences, University of Mississippi, University, \\ MS, USA: ${ }^{3}$ The Jackson Heart Study, University of Mississippi Medical Center, Jackson, MS, USA: ${ }^{4}$ USDA \\ Agricultural Research Service, Little Rock, AR, USA
}

Submitted 4 April 2007: Accepted 13 September 2007: First published online 6 December 2007

\begin{abstract}
Objectives: Intake and status of carotenoids have been associated with chronic disease. The objectives of this study were to examine the association between carotenoid intakes as measured by two regional food-frequency questionnaires (FFQs) and their corresponding measures in serum, and to report on dietary food sources of carotenoids in Jackson Heart Study (JHS) participants.

Design: Cross-sectional analysis of data for 402 African American men and women participating in the Diet and Physical Activity Sub-Study (DPASS) of the JHS.

Results: Mean serum carotenoid concentrations and intakes in this population were comparable to those reported for the general US population. After adjustment for covariates, correlations between serum and dietary measures of each carotenoid, for the average of the recalls (deattenuated), the short FFQ and the long FFQ, respectively, were: $0.37,0.35$ and 0.21 for $\alpha$-carotene; $0.35,0.26$ and 0.28 for total (diet plus supplements) $\beta$-carotene; $0.25,0.17$ and 0.20 for dietary $\beta$-carotene; $0.42,0.34$ and 0.26 for $\beta$-cryptoxanthin; $0.33,0.15$ and 0.17 for lutein plus zeaxanthin; and 0.37 , 0.19 and 0.14 for lycopene. Major dietary sources of $\alpha$-carotene were orange vegetables; of $\beta$-carotene and lutein plus zeaxanthin, mustard, turnip and collard greens; of $\beta$-cryptoxanthin, orange juice; and of lycopene, tomato juice.

Conclusions: On average, carotenoid intakes and serum concentrations are not lower in this southern African American population than the general US population. The two regional FFQs developed for a southern US population and used as dietary assessment tools in the JHS appear to provide reasonably valid information for most of these carotenoids.
\end{abstract}

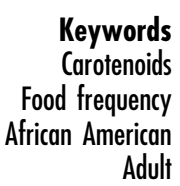

Adult
Approximately 600 different carotenoids are known to exist in nature ${ }^{(1)}$. Whereas plants, fungi, algae and bacteria can synthesise these compounds, animals cannot and therefore need to obtain them from their $\operatorname{diet}^{(2)}$. The only clearly proven function of carotenoids in humans is their provitamin A activity. The major carotenoids found in human sera are $\alpha$ - and $\beta$-carotene, lycopene, lutein, zeaxanthin and cryptoxanthin. Of these, $\alpha$ - and $\beta$-carotene and $\beta$-cryptoxanthin have provitamin A activity ${ }^{(3)}$.

Recently, non provitamin A-related activities of carotenoids have received attention. These include possible contribution to reducing the risk for diseases such as cardiovascular disease $(\mathrm{CVD})^{(4-6)}$, cancer $^{(7-9)}$, cognitive decline ${ }^{(10)}$, age-related macular degeneration and cataract ${ }^{(11-13)}$. However, many of these associations are yet to be proved conclusively.

CVD has been a dominant cause of death in the USA for the past 50 or more years. Heart disease and stroke are the first and third specific causes of death in this country. Within the USA, African Americans have the highest rates of morbidity and mortality from CVD, and the southeastern part of the USA has the highest rates of hospitalisations due to stroke and heart failure ${ }^{(14)}$. Much of the available data relating risk factors and CVD have come from predominantly white populations ${ }^{(15)}$. The Jackson Heart Study (JHS) was therefore initiated to investigate the causes of CVD in an all African American cohort based in Jackson, Mississippi ${ }^{(16)}$. 
Given the health disparities that exist among African Americans with respect to CVD and the protective role that carotenoid intake and status may play in the prevention of this group of diseases, the objectives of the current study were:

1. To assess the dietary intake and serum concentrations of $\alpha$ - and $\beta$-carotene, $\beta$-cryptoxanthin, lutein plus zeaxanthin, and lycopene among participants of the Diet and Physical Activity Sub-Study (DPASS) of the JHS using three dietary assessment tools - two regional food-frequency questionnaires (FFQs) and four $24 \mathrm{~h}$ recalls.

2. To evaluate the associations between carotenoid intake measures and serum concentrations.

3. To identify the relative contributions of foods to carotenoid intakes in this population.

\section{Methods}

\section{Population}

Participants were from the JHS, a single-site prospective epidemiologic investigation of CVD among African Americans from the Jackson, Mississippi metropolitan area. The JHS baseline data collection took place from late 2000 until early 2004. Data on conventional as well as new and emerging risk factors of CVD were collected on a randomly selected representative sample of African Americans aged 34-84 years residing in the Hinds, Madison and Rankin counties surrounding Jackson, Mississippi. A more detailed description of the original study has been published elsewhere ${ }^{(17)}$.

\section{Selection of study sample}

A subset of participants $(n=499)$ from the JHS cohort $(N=5302)$ was selected for the JHS-DPASS. The aim of DPASS was to provide data for validation of the diet and physical activity instruments used for the entire cohort of the JHS. DPASS investigators identified potential participants for DPASS based on certain criteria. The goal was to include an equal number of men and women from younger (34-64 years) and older ( 65 years and older) age groups, lower and higher socio-economic status, as well as lower and higher physical activity groups. Participants were enrolled into DPASS on a rolling basis and data were collected throughout the year.

The data presented here include all DPASS participants with complete dietary and serum carotenoid data. The Institutional Review Board of the University of Mississippi approved the DPASS protocols, and all subjects gave written informed consent for their participation.

\section{Dietary assessment}

The most widely used FFQs in the USA were designed to capture foods most commonly consumed in the general
US population $^{(18,19)}$. This can lead to incorrect estimation of the dietary intakes of population subgroups and ethnicities who have dietary intakes and practices that are different from those of the 'general' population. These errors can ultimately lead to extensive misclassification.

The Lower Mississippi Delta Nutrition Intervention Research Initiative (LMD NIRI), funded by the US Department of Agriculture (USDA) Agricultural Research Service, conducted a telephone survey in the Delta region to collect representative dietary data using $24 \mathrm{~h}$ dietary recalls. These data were used to develop a new FFQ designed for use in the LMD region. Foods reported in the recalls were grouped into food groups based on nutrient content and culinary use. These food groups were then ranked based on their relative contributions to energy and nutrients. Foods contributing at least $0.5 \%$ to any of the selected nutrients were included on the FFQ food list. Serving sizes were also modified to reflect those reported during the recalls. Data from the survey were also used to provide weighting and recipe information for the nutrient database used to analyse questionnaire responses. The Delta NIRI FFQ was also field-tested in the LMD and Jackson, Mississippi region using a modified cognitive interviewing methodology. The resulting Delta NIRI FFQ has 283 items (long FFQ). Further details regarding development of this regional FFQ are available elsewhere $^{(20)}$. A shortened version with 158 items (short FFQ) was specifically developed for use in the JHS. This version does not eliminate food groups, but rather includes less detail by collapsing similar items for efficiency in reporting. Foods within line items were weighted, based on the frequency of consumption in the Delta $24 \mathrm{~h}$ recalls, for calculation of nutrient content. To avoid overestimation of fruit and vegetable intake on the long FFQ, summary questions on overall fruit and vegetable intake were asked. Nutrient intakes from the responses on individual fruits and vegetables were then adjusted proportionally to these responses for overall frequency. Both FFQs were used as dietary assessment tools in the DPASS.

Four $24 \mathrm{~h}$ recalls were used to measure the 'quantitative' intake of DPASS participants. Trained and certified dietitians collected these recalls using the Nutrient Data System developed by the University of Minnesota. To stabilise variability of intake, participants provided two weekdays and two weekend days for the recalls.

The DPASS encounters included an initial administration of the short FFQ, followed by four $24 \mathrm{~h}$ recalls scheduled approximately one month apart, and finally administration of the long FFQ, scheduled approximately one week after administration of the last recall. The short FFQs were administered by trained clinic staff while the recalls and long FFQs were administered by trained dietitians. All FFQs were reviewed by DPASS staff for entry errors. Furthermore, $5 \%$ of all FFQs and all recalls were audio-taped for quality control purposes, and were reviewed by the DPASS principal investigator. Retraining 
was conducted whenever problems with quality or completeness were identified by the review. Details regarding the methodology used for the DPASS have been published elsewhere ${ }^{(21)}$.

\section{Laboratory analyses}

Participants provided blood samples on the day of the baseline interview, which took place on the day of administration of the short FFQ and, on average, a year prior to administration of the long FFQ. Blood samples from fasting $(12 \mathrm{~h})$ participants were collected in Vacutainer tubes and centrifuged at $3000 \mathrm{~g}$ for $10 \mathrm{~min}$ at $4^{\circ} \mathrm{C}$. Serum was separated and frozen at $-70^{\circ} \mathrm{C}$ until analysed for carotenoids. Estimation of carotenoids was performed using high-performance liquid chromatography as described by Yeum et al. ${ }^{(22)}$. Serum cholesterol concentrations were determined according to methods described previously ${ }^{(23)}$.

\section{Assessment of covariates}

Information on age and smoking status was collected by questionnaire at either the home induction visit or at the time of the participant's clinic visit. Supplement use was obtained from responses on the FFQs. Both height and weight were measured by trained technicians at the time of the clinic visit. Anthropometric procedures have been detailed elsewhere ${ }^{(17)}$. Body mass index (BMI) was calculated from these measurements as weight/height ${ }^{2}$ $\left(\mathrm{kg} / \mathrm{m}^{2}\right)$. Information on month of administration of the FFQ was obtained from the FFQ.

\section{Statistical analyses}

DPASS participants for whom there were no serum samples provided for carotenoid analysis $(n=39)$, or who reported energy intake outside the plausible range $(<2510$ or $>16736 \mathrm{~kJ} / \mathrm{d})$ on any of the FFQs or mean of the four $24 \mathrm{~h}$ recalls $(n=53)$, or who had more than $10 \%$ of the questions blank on any FFQ $(n=5)$, were excluded from analyses. This resulted in a sample of 402 individuals.

Both intake and biochemical measures of carotenoids were skewed, and were log-transformed prior to analyses. Descriptive analyses were performed to assess sex differences using general linear models for continuous variables and $\chi^{2}$ analyses for categorical data for demographics of the population and serum carotenoid and lipid measurements. Pearson's correlations were used to examine associations between intake and serum measures for each of the carotenoids. Of these carotenoids, only $\beta$-carotene was commonly present in dietary supplements at the time of this study. Therefore, we estimated the total (diet plus supplement) and dietary associations between this carotenoid and its corresponding serum measure. Partial correlations were used to adjust for age, sex, BMI, energy intake from the corresponding dietary instrument used, serum total cholesterol concentrations and smoking status. Day-today within-person variation across $24 \mathrm{~h}$ dietary recalls can attenuate correlations between nutrient intakes derived from the mean of the dietary recalls and the serum carotenoid estimates. We therefore calculated the intrato inter-person variance for the nutrient intakes from the four $24 \mathrm{~h}$ recalls. The following formula was used to calculate the deattenuated correlation coefficients: $r_{t}=r_{\mathrm{o}} \sqrt{1+\operatorname{intra}_{x} / \text { inter }_{x} / n_{x}}$, where $r_{\mathrm{o}}$ is the observed correlation coefficient between the nutrient intake as determined from the mean of the four $24 \mathrm{~h}$ recalls and the corresponding serum measure, intra $x_{x}$ is the intra-subject variation, inter ${ }_{x}$ is the inter-subject component of variance for each nutrient and $n$ is the number of days of recalls, which in the present study was four days. Deattenuated correlations for adjusted variables were calculated after adjustment by the residual method.

Using the General Linear Models (GLM) procedure, with adjustment for age, sex, energy intake from the appropriate assessment method, month of administration (for the FFQ only), BMI, serum cholesterol concentrations and smoking status, we estimated the mean carotenoid concentrations for respective quartiles of total carotenoid intake. We also ranked the main sources of carotenoids for the long FFQ by calculating the percentage contribution of each food item (or supplement) to the total intake of each carotenoid. All $\alpha$ values were set at the 0.05 level. The SAS statistical software package, release version 9.1 (SAS Institute, Cary, NC, USA) was used for all analyses.

\section{Results}

The mean age of subjects did not differ significantly between men and women (approximately 60 vs. 62 years) (Table 1). Mean age-adjusted BMI was higher for women than men (approximately $32 \mathrm{vs} .29 \mathrm{~kg} / \mathrm{m}^{2}, P<0.05$ ). A lower percentage of women than men were current smokers. As reported on either FFQ, significantly more women than men reported taking supplements. Also, use of supplements containing $\beta$-carotene was higher in women compared with men.

Women had higher serum concentrations of highdensity lipoprotein cholesterol and total cholesterol compared with men $(P<0.05)$ (Table 2$)$. No differences were observed for serum low-density lipoprotein cholesterol or triacylglycerol concentrations. Women had significantly lower serum lycopene concentrations $(P<0.05)$ than to men. There were no other statistically significant differences for serum carotenoids.

Median intakes of the carotenoids estimated by the two FFQs and the average of four $24 \mathrm{~h}$ recalls are shown in Table 3. For illustration, median values from either of the FFQs that were $15 \%$ higher or lower than those reported 
Table 1 Characteristics of the JHS-DPASS participantsł

\begin{tabular}{|c|c|c|c|c|}
\hline \multirow[b]{2}{*}{ Variable } & \multicolumn{2}{|c|}{ Men $(n=155)$} & \multicolumn{2}{|c|}{ Women $(n=247)$} \\
\hline & Mean & SEM & Mean & SEM \\
\hline Age (years) $(n=402)$ & $60 \cdot 2$ & 0.8 & 61.5 & 0.6 \\
\hline BMI $\left(\mathrm{kg} / \mathrm{m}^{2}\right)(n=401)$ & 29.4 & 0.5 & $31.9^{*}$ & 0.4 \\
\hline \multicolumn{5}{|l|}{ Smoking status $(\%)(n=402)$} \\
\hline Never & \multicolumn{2}{|c|}{$51 \cdot 6$} & \multicolumn{2}{|c|}{$75 \cdot 3$} \\
\hline Former & \multirow{2}{*}{\multicolumn{2}{|c|}{$\begin{array}{l}35.5 \\
12.9\end{array}$}} & \multicolumn{2}{|c|}{$18 \cdot 2$} \\
\hline Current & & & \multicolumn{2}{|c|}{$6 \cdot 5^{\star}$} \\
\hline \multicolumn{5}{|l|}{ Supplement use $(n=402)$} \\
\hline Short FFQ (\%) & \multicolumn{2}{|c|}{$47 \cdot 1$} & \multicolumn{2}{|c|}{$63 \cdot 2^{*}$} \\
\hline Users of $\beta$-carotene-containing supplements (\%) & \multicolumn{2}{|c|}{34.8} & \multicolumn{2}{|c|}{$44 \cdot 5^{\star}$} \\
\hline Long FFQ (\%) & \multirow{2}{*}{\multicolumn{2}{|c|}{$\begin{array}{l}51.0 \\
39.3\end{array}$}} & \multicolumn{2}{|c|}{$67 \cdot 6^{\star}$} \\
\hline Users of $\beta$-carotene-containing supplements (\%) & & & \multicolumn{2}{|c|}{$50 \cdot 5^{\star}$} \\
\hline
\end{tabular}

JHS, Jackson Heart Study; DPASS, Diet and Physical Activity SubStudy; SEM, standard error of the mean; BMI, body mass index; FFQ, food-frequency questionnaire.

*Significantly different from men: $P<0.05$.

$\ddagger$ Sex groups were compared by Generalised Linear Models after adjusting for age.

Table 2 Serum concentrations of carotenoids and lipoproteins of the JHS-DPASS participantsł,, ,॥

\begin{tabular}{|c|c|c|c|c|}
\hline \multirow[b]{2}{*}{ Serum measurement } & \multicolumn{2}{|c|}{ Men } & \multicolumn{2}{|c|}{ Women } \\
\hline & Mean & SEM & Mean & SEM \\
\hline$\alpha$-Carotene $(\mu \mathrm{mol} / \mathrm{l})(n=402)$ & 0.07 & 0.005 & 0.07 & 0.004 \\
\hline$\beta$-Carotene $(\mu \mathrm{mol} / \mathrm{l})(n=402)$ & 0.62 & 0.05 & 0.72 & 0.04 \\
\hline Non $\beta$-carotene supplement users $(n=238)$ & 0.51 & 0.06 & 0.64 & 0.05 \\
\hline$\beta$-Carotene supplement users $(n=164)$ & 0.84 & 0.09 & 0.82 & 0.07 \\
\hline$\beta$-Cryptoxanthin $(\mu \mathrm{mol} / \mathrm{l})(n=402)$ & 0.17 & 0.01 & 0.18 & 0.01 \\
\hline Lutein plus zeaxanthin $(\mu \mathrm{mol} / \mathrm{l})(n=402)$ & 0.32 & 0.01 & 0.32 & 0.01 \\
\hline Lycopene $(\mu \mathrm{mol} / \mathrm{l})(n=402)$ & 1.44 & 0.06 & $1 \cdot 24^{*}$ & 0.05 \\
\hline LDL-C $(\mathrm{mmol} / \mathrm{l})(n=398)$ & 3.23 & 0.07 & $3 \cdot 20$ & 0.06 \\
\hline $\mathrm{HDL}-\mathrm{C}(\mathrm{mmol} / \mathrm{l})(n=401)$ & 1.21 & 0.03 & $1.47^{\star}$ & 0.02 \\
\hline Total cholesterol (mmol/l) $(n=402)$ & 5.00 & 0.08 & $5 \cdot 26^{*}$ & 0.07 \\
\hline Triacylglycerols $(\mathrm{mmol} / \mathrm{l})(n=402)$ & 1.25 & 0.08 & 1.30 & 0.07 \\
\hline
\end{tabular}

JHS, Jackson Heart Study; DPASS, Diet and Physical Activity Sub-Study; SEM, standard error of the mean; LDL-C, low-density lipoprotein cholesterol; HDL-C, high-density lipoprotein cholesterol.

${ }^{*}$ Mean values were significantly different from those for men: $P<0.05$.

¥Sex groups were compared by Generalised Linear Models after adjusting for age.

\$Pairwise comparisons, using log-transformed variables, were done by sex.

$\| \beta$-Carotene supplement use was based on reported use on the short food-frequency questionnaire.

Table 3 Median (25th, 75th percentile) intakes of carotenoid nutrients of the JHS-DPASS participants

\begin{tabular}{|c|c|c|c|c|c|c|}
\hline \multirow[b]{2}{*}{ Dietary nutrient } & \multicolumn{2}{|c|}{ Average of four $24 \mathrm{~h}$ recalls } & \multicolumn{2}{|c|}{ Short FFQ } & \multicolumn{2}{|c|}{ Long FFQ } \\
\hline & Median & (P25, P75) & Median & (P25, P75) & Median & (P25, P75) \\
\hline \multicolumn{7}{|l|}{ Men $(n=155)$} \\
\hline Energy (kJ/d) & 8304 & $(6893,9951)$ & 8320 & $(6323,11000)$ & 8453 & $(6227,11322)$ \\
\hline$\alpha$-Carotene $(\mu \mathrm{g} / \mathrm{d})$ & 177 & $(41,548)$ & $385+t$ & $(247,593)$ & $328+t$ & $(180,509)$ \\
\hline Total $\beta$-carotene $(\mu \mathrm{g} / \mathrm{d})$ & 3178 & $(1696,5360)$ & 2886 & $(2304,3682)$ & $2685+t$ & $(1776,4575)$ \\
\hline Dietary $\beta$-carotene $(\mu \mathrm{g} / \mathrm{d})$ & 2928 & $(1584,6099)$ & 2802 & $(2147,3529)$ & $2205+t$ & $(1534,3424)$ \\
\hline$\beta$-Cryptoxanthin $(\mu \mathrm{g} / \mathrm{d})$ & 85 & $(30,183)$ & $108+t$ & $(62,187)$ & $113+t$ & $(57,193)$ \\
\hline Lutein plus zeaxanthin $(\mu \mathrm{g} / \mathrm{d})$ & 2935 & $(1345,5261)$ & $2259+t$ & $(1735,3065)$ & $1849+t$ & $(1311,2594)$ \\
\hline \multirow{2}{*}{\multicolumn{7}{|c|}{ Women $(n=247)$}} \\
\hline & & & & & & \\
\hline Energy $(\mathrm{kJ} / \mathrm{d})$ & $6449+$ & $(5292,8010)$ & $6894 t$ & $(5463,9107)$ & 7243 & $(5762,8923)$ \\
\hline$\alpha$-Carotene $(\mu \mathrm{g} / \mathrm{d})$ & $144+$ & $(37,487)$ & $349+t$ & $(221,517)$ & $251+t,+$ & $(143,431)$ \\
\hline Total $\beta$-carotene $(\mu \mathrm{g} / \mathrm{d})$ & 3044 & $(2029,6525)$ & 3048 & $(2419,4100)$ & 2707 & $(1746,4057)$ \\
\hline Dietary $\beta$-carotene $(\mu \mathrm{g} / \mathrm{d})$ & 2770 & $(1409,4933)$ & 2561 & $(1940,3312)$ & $2211+t$ & $(1528,2992)$ \\
\hline$\beta$-Cryptoxanthin $(\mu \mathrm{g} / \mathrm{d})$ & 98 & $(43,171)$ & 111 & $(61,197)$ & $126+t$ & $(57,199)$ \\
\hline Lutein plus zeaxanthin $(\mu \mathrm{g} / \mathrm{d})$ & 2607 & $(1338,5152)$ & $2149+t$ & $(1676,2832)$ & $1927+t$ & $(1428,616)$ \\
\hline Lycopene $(\mu \mathrm{g} / \mathrm{d})$ & $1467 \dagger$ & $(502,3827)$ & $2789+t, \dagger$ & $(1622,4248)$ & $2600+t, t$ & $(1434,4181)$ \\
\hline
\end{tabular}

JHS, Jackson Heart Study; DPASS, Diet and Physical Activity Sub-Study; FFQ, food-frequency questionnaire.

tMedian value is $>15 \%$ different from that for men.

t+Median value is $>15 \%$ different from that for the recalls. 
Table 4 Crude and adjusted Pearson's correlations between serum carotenoid nutrient biomarkers and carotenoid intakes in the JHS-DPASS $\ddagger, \S, \|, \uparrow$

\begin{tabular}{lccc}
\hline $\begin{array}{l}\text { Nutrient biomarker } \\
\text { Crude }\end{array}$ & $\begin{array}{c}\text { Four } 24 \mathrm{~h} \\
\text { recalls } \$\end{array}$ & $\begin{array}{c}\text { Short } \\
\mathrm{FFQ}^{*}, \|\end{array}$ & $\begin{array}{c}\text { Long } \\
\mathrm{FFQ}^{*}, \|\end{array}$ \\
$\quad$-Carotene & & & \\
$\quad$ Total $\beta$-carotene & 0.41 & 0.32 & 0.18 \\
Dietary $\beta$-carotene & 0.35 & 0.22 & 0.28 \\
$\beta$-Cryptoxanthin & 0.44 & 0.12 & 0.21 \\
Lutein plus & 0.39 & 0.29 & 0.25 \\
zeaxanthin & & 0.13 & 0.20 \\
Lycopene & 0.40 & 0.24 & 0.14 \\
Adjusted & & & \\
$\alpha$-Carotene & 0.37 & 0.35 & 0.21 \\
Total $\beta$-carotene & 0.35 & 0.26 & 0.28 \\
Dietary $\beta$-carotene & 0.25 & 0.17 & 0.20 \\
$\beta$-Cryptoxanthin & 0.42 & 0.34 & 0.26 \\
Lutein plus & 0.33 & 0.15 & 0.17 \\
zeaxanthin & & & \\
Lycopene & 0.37 & 0.19 & 0.14
\end{tabular}

JHS, Jackson Heart Study; DPASS, Diet and Physical Activity Sub-Study; $F F Q$, food-frequency questionnaire.

${ }^{*} P<0.05$.

‡Both intake and serum carotenoid variables were log-transformed.

\$For recalls, both crude and adjusted correlations calculated are deattenuated. Adjustment is for age, sex, energy intake from the appropriate assessment tool, body mass index (BMI), serum cholesterol and smoking status.

IFor FFQs, adjustment is for age, sex, energy intake from the appropriate assessment tool, BMI, serum cholesterol, smoking status and month of FFQ administration.

- For crude correlations, $N=402$ for all assessment methods. For adjusted correlations, because of missing data, $N=401$ for the short FFQ and recalls and $N=400$ for the long FFQ.

by the recalls are marked with ' $\dagger \uparrow$ '. For men, as compared with the recalls, both the short and the long FFQ overestimated $\alpha$-carotene, $\beta$-cryptoxanthin and lycopene and underestimated lutein plus zeaxanthin. The long FFQ underestimated both dietary and total $\beta$-carotene intakes. For women, both the long and the short FFQ overestimated $\alpha$-carotene and lycopene while underestimating lutein plus zeaxanthin. The long FFQ underestimated dietary $\beta$-carotene intakes and overestimated $\beta$-cryptoxanthin intakes compared with the recalls.

Median values for nutrient differences between men and women higher or lower than $15 \%$ as estimated by each assessment tool are indicated by ' $\uparrow$ '. Men had higher intakes of $\alpha$-carotene on the recalls and the long FFQ and of lycopene for all the assessment tools. Energy intakes were also higher for men as estimated by the recalls and the short FFQ (Table 3).

We examined simple and adjusted Pearson's correlations between carotenoid intakes and serum concentrations (Table 4). Correlations were adjusted for age, BMI, serum cholesterol concentration, smoking status, month of administration (only for the FFQs) and energy intake from the respective assessment tool. In general, the adjusted coefficients were higher for the questionnaires than their crude counterparts; particularly for the short FFQ. For the average of the recalls, deattenuated adjusted correlations either remained the same or decreased slightly compared with their deattenuated crude counterparts. For the short FFQ, adjusted correlations ranged from 0.35 for $\alpha$-carotene to 0.15 for lutein plus zeaxanthin. For the long FFQ, adjusted correlations ranged from 0.28 for total $\beta$-carotene to 0.14 for lycopene. For the average of the recalls, deattenuated adjusted correlations ranged from 0.42 for $\beta$-cryptoxanthin to 0.25 for dietary $\beta$-carotene.

We also examined the mean serum concentrations of carotenoids by quartiles of total intake as measured by each of the dietary assessment instruments. For $\alpha$-carotene and $\beta$-carotene, serum measures were each higher with increasing intake and levelled at the highest intake quartiles. For $\beta$-cryptoxanthin, there was a linear trend between intake and serum concentration. For lycopene, weaker trends were seen. The associations for lutein and zeaxanthin were weaker than those seen for the other carotenoids (Table 5).

We identified and ranked the foods that contributed to the majority of the dietary intakes of these carotenoids in this population as assessed by the long FFQ (Table 6). Top dietary contributors of $\alpha$-carotene were orange vegetables (both raw and cooked), whereas dietary sources of $\beta$-carotene were mustard, turnip and collard greens followed by sweet potato. When supplements were considered, they provided $22 \%$ of $\beta$-carotene. Orange juice provided most of the $\beta$-cryptoxanthin. Leafy greens like mustard, turnip and collard were the top contributors of lutein and zeaxanthin, providing almost $40 \%$ of the carotenoid. Tomato juice and pasta preparations were the main sources of lycopene.

\section{Discussion}

CVD is a major health concern among African Americans. Dietary carotenoids have been implicated in decreased risk for CVD. The purpose of this study was to assess the intake and serum concentrations of $\alpha$ - and $\beta$-carotene, $\beta$-cryptoxanthin, lutein plus zeaxanthin, and lycopene among participants of the JHS-DPASS using three dietary assessment tools (two regional FFQs and the average of four $24 \mathrm{~h}$ recalls) and to assess associations between intake measures and serum concentrations. In addition, we identified the relative contributions of foods to carotenoid intakes in this population.

Despite reports of low fruit and vegetable intake in this region $^{(24)}$, the carotenoid intakes of the JHS-DPASS participants were within the 50th-90th percentile values from the Third National Health and Nutrition Examination Survey (NHANES III) for similar age and sex groups for all carotenoids except lycopene, where the intakes were within the 50 th -75 th percentile range ${ }^{(25)}$. In general, the biochemical status of the carotenoids was also within the 50th-75th percentile range for African American participants of the NHANES III examination ${ }^{(26)}$ and 
Table 5 Mean serum concentrations of carotenoids ( $\mu \mathrm{mol} / \mathrm{l})$ for the JHS-DPASS participants by quartile of carotenoid intake as estimated by the different dietary assessment instrumentsł,§

\begin{tabular}{|c|c|c|c|c|c|c|c|c|c|c|}
\hline & \multicolumn{2}{|c|}{$\alpha$-Carotene } & \multicolumn{2}{|c|}{$\beta$-Carotene } & \multicolumn{2}{|c|}{$\beta$-Cryptoxanthin } & \multicolumn{2}{|c|}{ Lutein plus zeaxanthin } & \multicolumn{2}{|c|}{ Lycopene } \\
\hline & Mean & SEM & Mean & SEM & Mean & SEM & Mean & SEM & Mean & SEM \\
\hline \multicolumn{11}{|c|}{ Short FFQ $(n=401)$} \\
\hline \multicolumn{11}{|c|}{ Carotenoid intake } \\
\hline Quartile 1 & 0.043 & 0.006 & 0.518 & 0.06 & 0.131 & 0.01 & 0.294 & 0.01 & 1.09 & 0.06 \\
\hline Quartile 2 & 0.059 & 0.006 & 0.684 & 0.06 & 0.166 & 0.01 & 0.320 & 0.01 & 1.26 & 0.06 \\
\hline Quartile 3 & 0.069 & 0.006 & 0.756 & 0.06 & 0.184 & 0.01 & 0.329 & 0.01 & 1.43 & 0.06 \\
\hline Quartile 4 & $0.094^{*}$ & 0.006 & $0.774^{\star}$ & 0.06 & $0.233^{*}$ & 0.01 & $0.336^{*}$ & 0.01 & $1.47^{*}$ & 0.06 \\
\hline \multicolumn{11}{|c|}{ Long FFQ $(n=401)$} \\
\hline \multicolumn{11}{|c|}{ Carotenoid intake } \\
\hline Quartile 1 & 0.053 & 0.006 & 0.470 & 0.06 & 0.142 & 0.01 & 0.283 & 0.01 & 1.21 & 0.07 \\
\hline Quartile 2 & 0.062 & 0.006 & 0.667 & 0.06 & 0.157 & 0.01 & 0.327 & 0.01 & 1.25 & 0.06 \\
\hline Quartile 3 & 0.065 & 0.006 & 0.793 & 0.06 & $0 \cdot 196$ & 0.01 & 0.318 & 0.01 & 1.37 & 0.07 \\
\hline Quartile 4 & $0.085^{*}$ & 0.006 & $0.798^{*}$ & 0.06 & $0.219^{*}$ & 0.01 & $0.351^{*}$ & 0.01 & $1.43^{*}$ & 0.07 \\
\hline \multicolumn{11}{|c|}{ Average of four $24 \mathrm{~h}$ recalls $(n=401)$} \\
\hline \multicolumn{11}{|c|}{ Carotenoid intake } \\
\hline Quartile 1 & 0.048 & 0.006 & 0.611 & 0.06 & 0.129 & 0.01 & 0.281 & 0.01 & 1.19 & 0.07 \\
\hline Quartile 2 & 0.064 & 0.006 & 0.612 & 0.06 & 0.171 & 0.01 & 0.305 & 0.01 & 1.26 & 0.07 \\
\hline Quartile 3 & 0.071 & 0.006 & 0.800 & 0.06 & 0.177 & 0.01 & 0.330 & 0.01 & 1.33 & 0.07 \\
\hline Quartile 4 & $0.081^{*}$ & 0.006 & $0 \cdot 717^{\star}$ & 0.06 & $0.237^{*}$ & 0.01 & $0.363^{*}$ & 0.01 & $1.48^{*}$ & 0.07 \\
\hline
\end{tabular}

JHS, Jackson Heart Study; DPASS, Diet and Physical Activity Sub-Study; FFQ, food-frequency questionnaire.

${ }^{*}$ Test for trend across quartiles: $P<0.05$.

‡Mean serum carotenoid concentrations adjusted for age, sex, energy intake from the appropriate assessment tool, body mass index, serum cholesterol, current smoker ( $\mathrm{Y} / \mathrm{N})$, month of administration (only for the FFQs).

$\S(1)$ For $\alpha$-carotene; median intakes in the quartile categories were 173, 289, 446, $733 \mu \mathrm{g} / \mathrm{d}$ on the short FFQ; 109, 227, 354, 689 $\mu \mathrm{g} / \mathrm{d}$ on the long FFQ; and 21, $67,290,782 \mu \mathrm{g} / \mathrm{d}$ on the average of the recalls.

(2) For $\beta$-carotene; median intakes in the quartile categories were $1950,2781,3372,4302 \mu \mathrm{g} / \mathrm{d}$ on the short FFQ; $1413,2312,3347,5165 \mu \mathrm{g} / \mathrm{d}$ on the long FFQ; and $863,2444,4256,7874 \mu \mathrm{g} / \mathrm{d}$ on the average of the recalls.

(3) For $\beta$-cryptoxanthin; median intakes in the quartile categories were 40, 86, 147, $230 \mu \mathrm{g} / \mathrm{d}$ on the short FFQ; 37, 83, 151, 268 $\mu \mathrm{g} / \mathrm{d}$ on the long FFQ; and 16,

$62,139,254 \mu \mathrm{g} / \mathrm{d}$ on the average of the recalls.

(4) For lutein plus zeaxanthin; median intakes in the quartile categories were 1436, 1896, 2465, 3575 $\mu \mathrm{g} / \mathrm{d}$ on the short FFQ; 1143 , 1591, 2119 , 3334 $\mu \mathrm{g} / \mathrm{d}$ on the long FFQ; and 912, 1893, 3991, $7697 \mu \mathrm{g} / \mathrm{d}$ on the average of the recalls.

(5) For lycopene; median intakes in the quartile categories were 1220, 2472, 3646, $6247 \mu \mathrm{g} / \mathrm{d}$ on the short FFQ; 1219, 2265, 3318, 5858 $\mu \mathrm{g} / \mathrm{d}$ on the long FFQ; and $36,918,2342,6999 \mu \mathrm{g} / \mathrm{d}$ on the average of the recalls.

similar to those reported for other populations ${ }^{(26-31)}$. Serum lycopene concentrations appeared higher than other published values. This did not appear to be due to a higher intake of dietary lycopene, but rather could be attributed to the inclusion of both cis and trans isomers of lycopene in our estimation of serum lycopene concentrations. Generally, the cis isomers are not included in lycopene estimations ${ }^{(32)}$. When we included only translycopene in the assessment, the age-adjusted serum trans-lycopene concentrations were 0.50 (standard error of the mean (SEM) 0.02) $\mu \mathrm{mol} / 1$ for men and 0.45 (SEM 0.01) $\mu \mathrm{mol} / \mathrm{l}$ for women, which were closer to values reported by others.

The FFQs used in this study were specifically developed for use with a southern US population. Correlations comparing intake measured with other assessment tools including the Block or Harvard FFQ and biochemical measures of carotenoids have demonstrated correlation coefficients ranging from 0.09 to 0.45 for various carotenoids $^{(28,30,33-37)}$, similar to our range of $0 \cdot 12$ to $0 \cdot 35$. Some of the lowest correlations seen were for lutein plus zeaxanthin. Lutein and zeaxanthin, unlike nutrients such as $\beta$-cryptoxanthin, are present in a wider variety of foods. This could make its estimation using FFQs with a limited number of food items difficult ${ }^{(38)}$.
The mean lycopene intakes obtained from both FFQs in general were higher than those from the recalls. This has also been previously reported by other researchers $^{(39)}$. Relatively weak correlations were also seen for lycopene with the long and the short FFQ compared with the average of the $24 \mathrm{~h}$ recalls. It is possible that the recalls capture processing techniques that may reflect availability of lycopene from tomato-containing products better than the FFQs, which make assumptions about the tomato content in foods such as pasta with meat dishes ${ }^{(40)}$. Besides this, researchers have suggested that the lack of correlation between intake and serum measures may be affected by several other factors including recent lycopene intake, age and genetics, as well as individual absorption capacity ${ }^{(40)}$.

The design of the DPASS included administration of the short FFQ at the time of the clinic visit. If the participant met the criteria for the diet sub-study, he or she was asked to join, and if the participant agreed, the first DPASS visit with administration of the first $24 \mathrm{~h}$ recall took place on average a month or two after the clinic visit. The next three $24 \mathrm{~h}$ recalls were scheduled to be administered approximately one month apart, and a week after the last recall, the participant was administered the long FFQ. As recruitment to the JHS was on a rolling basis, participants 
Table 6 Main contributors to carotenoid intakes among the JHS-DPASS participantsł

\begin{tabular}{|c|c|}
\hline Nutrient & $\begin{array}{l}\text { Percentage } \\
\text { contribution }\end{array}$ \\
\hline \multicolumn{2}{|l|}{$\alpha$-Carotene } \\
\hline Orange vegetables, cooked & $25 \cdot 0$ \\
\hline Orange vegetables, raw & 22.5 \\
\hline Mixed dishes with chicken or turkey & 14.8 \\
\hline Mixed dishes with beef & 13.9 \\
\hline Water-based vegetable or tomato soup & $5 \cdot 1$ \\
\hline \multicolumn{2}{|l|}{$\beta$-Carotene (dietary sources only) } \\
\hline Mustard greens, turnip greens \& collard greens & 17.9 \\
\hline Sweet potato & $17 \cdot 0$ \\
\hline Orange vegetables, cooked & 7.9 \\
\hline Orange vegetables, raw & 6.4 \\
\hline Cantaloupe & 5.4 \\
\hline Mixed dishes with beef & $5 \cdot 0$ \\
\hline \multicolumn{2}{|l|}{$\beta$-Carotene (diet plus supplement sources) } \\
\hline Supplements & 22.4 \\
\hline Mustard greens, turnip greens \& collard greens & 13.9 \\
\hline Sweet potato & 13.1 \\
\hline Orange vegetables, cooked & $6 \cdot 1$ \\
\hline \multicolumn{2}{|l|}{$\beta$-Cryptoxanthin } \\
\hline Orange juice & $40 \cdot 2$ \\
\hline Fortified citrus fruit juices & 27.5 \\
\hline Baked beans with pork & $8 \cdot 1$ \\
\hline Oranges & $6 \cdot 9$ \\
\hline Watermelon & $5 \cdot 7$ \\
\hline \multicolumn{2}{|l|}{ Lutein plus zeaxanthin } \\
\hline Mustard greens, turnip greens \& collard greens & 37.4 \\
\hline Mixed green leafy vegetables & 6.9 \\
\hline \multicolumn{2}{|l|}{ Lycopene } \\
\hline Tomato juice & $22 \cdot 3$ \\
\hline Mixed pasta dishes with beef & 11.5 \\
\hline Watermelon & 11.0 \\
\hline Baked beans with pork & $9 \cdot 6$ \\
\hline Mixed dishes with beef & $8 \cdot 7$ \\
\hline Gumbo soup & $5 \cdot 0$ \\
\hline
\end{tabular}

JHS, Jackson Heart Study; DPASS, Diet and Physical Activity Sub-Study. $\ddagger$ Those contributing at least $5 \%$ of intake on the long food-frequency questionnaire are listed.

enrolled into the DPASS on a rolling basis as well. Because the short FFQ was administered on the day of the blood draw (date of clinic visit), it could be expected that the correlations between carotenoid intake and biochemical status may be artefactually higher than for the FFQ administered later; however this was not the case. Correlations for $\beta$-carotene and lutein plus zeaxanthin were higher for the long FFQ than for the short, despite the greater distance in time between measures.

In this population of African Americans, orange vegetables were the top contributors to $\alpha$-carotene intake and greens and sweet potato were the top contributors to $\beta$-carotene intake. In a study conducted in the LMD region ${ }^{(20)}$, we previously reported that sweet potatoes were the top contributor to vitamin A intakes in the African American subgroup. Citrus fruit juices were the main contributors of $\beta$-cryptoxanthin intakes in this population. This has been reported in several diverse study populations ${ }^{(31,41,42)}$. Dark green leafy vegetables were the main source of lutein plus zeaxanthin. Nebeling et $a l .{ }^{(43)}$ reported similar findings in the African American subgroup of a national survey. In our study, tomato and tomato products were the top contributors of lycopene intake. This is in agreement with other studies conducted in the USA, where most of the lycopene is accounted for by tomato and tomato-containing products ${ }^{(44)}$.

Contrary to our expectation, carotenoid intakes and status did not appear to be lower in this population of southern African American adults than in the general US population. The deattenuated adjusted correlations obtained using the $24 \mathrm{~h}$ recalls were higher than those obtained from either FFQ. This could indicate that multiple recalls may be a better way to capture carotenoid intake. However, the range of correlations seen with these FFQs is similar to those published from validation studies of carotenoids with other FFQs. This, taken with the advantages of single administration and lower cost, suggests that FFQs provide relatively valid and useful measures of carotenoid intake in this population.

\section{Acknowledgements}

The authors have no conflicts of interest to report. This research was supported by NIH contracts N01-HC-95170, N01-HC-95171 and N01-HC-95172 from the National Heart, Lung, and Blood Institute and the National Center for Minority Health and Health Disparities; and by USDA Agricultural Research Service contracts \#6251-53000-003OOD and \#58-1950-7-707. S.A.T. performed the analysis and drafted the paper as part of her PhD thesis at Tufts University, E.J.J. directed the laboratory analysis and contributed to the interpretation of laboratory measures, T.C.C. directed the dietary data collection, H.A.T. is the principal investigator of the Jackson Heart Study, M.L.B. contributed to the dietary data collection and interpretation, K.L.T. oversaw the design, analysis and writing for this manuscript. All authors reviewed earlier drafts for content and form and approved the final version.

\section{References}

1. Olson JA \& Krinsky NI (1995) Introduction: the colorful, fascinating world of the carotenoids: important physiologic modulators. FASEB J 9, 1547-1550.

2. Mayne ST (1996) Beta-carotene, carotenoids, and disease prevention in humans. FASEB J 10, 690-701.

3. Olson JA (1999) Bioavailability of carotenoids. Arch Latinoam Nutr 49, Suppl. 1, 21S-25S.

4. Rissanen T, Voutilainen S, Nyyssonen K, Salonen R \& Salonen JT (2000) Low plasma lycopene concentration is associated with increased intima-media thickness of the carotid artery wall. Arterioscler Thromb Vasc Biol 20, $2677-2681$.

5. Hak AE, Ma J, Powell CB, Campos H, Gaziano JM, Willett WC \& Stampfer MJ (2004) Prospective study of plasma carotenoids and tocopherols in relation to risk of ischemic stroke. Stroke 35, 1584-1588.

6. Gaziano JM, Manson JE, Branch LG, Colditz GA, Willett WC \& Buring JE (1995) A prospective study of consumption of 
carotenoids in fruits and vegetables and decreased cardiovascular mortality in the elderly. Ann Epidemiol 5, 255-260.

7. Ziegler RG, Mason TJ, Stemhagen A, Hoover R, Schoenberg JB, Gridley G, Virgo PW \& Fraumeni JF Jr (1986) Carotenoid intake, vegetables, and the risk of lung cancer among white men in New Jersey. Am J Epidemiol 123, 1080-1093.

8. Ziegler RG (1991) Vegetables, fruits, and carotenoids and the risk of cancer. Am J Clin Nutr 53, Suppl. 1, 251S-259S.

9. Potischman N, McCulloch CE, Byers T et al. (1990) Breast cancer and dietary and plasma concentrations of carotenoids and vitamin A. Am J Clin Nutr 52, 909-915.

10. Rinaldi P, Polidori MC, Metastasio A, Mariani E, Mattioli P, Cherubini A, Catani M, Cecchetti R, Senin U \& Mecocci P (2003) Plasma antioxidants are similarly depleted in mild cognitive impairment and in Alzheimer's disease. Neurobiol Aging 24, 915-919.

11. Seddon JM, Ajani UA, Sperduto RD et al. (1994) Dietary carotenoids, vitamins $\mathrm{A}, \mathrm{C}$, and $\mathrm{E}$, and advanced agerelated macular degeneration. Eye Disease Case-Control Study Group. JAMA 272, 1413-1420.

12. Chasan-Taber L, Willett WC, Seddon JM, Stampfer MJ, Rosner B, Colditz GA, Speizer FE \& Hankinson SE (1999) A prospective study of carotenoid and vitamin A intakes and risk of cataract extraction in US women. Am J Clin Nutr 70, 509-516.

13. Mares-Perlman JA, Fisher AI, Klein R, Palta M, Block G, Millen AE \& Wright JD (2001) Lutein and zeaxanthin in the diet and serum and their relation to age-related maculopathy in the Third National Health and Nutrition Examination Survey. Am J Epidemiol 153, 424-432.

14. Mensah GA, Mokdad AH, Ford ES, Greenlund KJ \& Croft JB (2005) State of disparities in cardiovascular health in the United States. Circulation 111, 1233-1241.

15. Sempos CT, Bild DE \& Manolio TA (1999) Overview of the Jackson Heart Study: a study of cardiovascular diseases in African American men and women. Am J Med Sci 317, 142-146.

16. Taylor HA Jr (2005) The Jackson Heart Study: an overview. Ethn Dis 15, Suppl. 6, S6-1-S6-3.

17. Taylor HA Jr, Wilson JG, Jones DW, Sarpong DF, Srinivasan A, Garrison RJ, Nelson C \& Wyatt SB (2005) Toward resolution of cardiovascular health disparities in African Americans: design and methods of the Jackson Heart Study. Ethn Dis 15, Suppl. 6, S6-4-S6-17.

18. Block G, Hartman AM, Dresser CM, Carroll MD, Gannon J \& Gardner L (1986) A data-based approach to diet questionnaire design and testing. Am J Epidemiol 124, 453-469.

19. Willett WC, Sampson L, Stampfer MJ, Rosner B, Bain C, Witschi J, Hennekens CH \& Speizer FE (1985) Reproducibility and validity of a semiquantitative food frequency questionnaire. Am J Epidemiol 122, 51-65.

20. Tucker KL, Maras J, Champagne C, Connell C, Goolsby S, Weber J, Zaghloul S, Carithers T \& Bogle ML (2005) A regional food-frequency questionnaire for the US Mississippi Delta. Public Health Nutr 8, 87-96.

21. Carithers T, Dubbert PM, Crook E, Davy B, Wyatt SB, Bogle ML, Taylor HA Jr \& Tucker KL (2005) Dietary assessment in African Americans: methods used in the Jackson Heart Study. Ethn Dis 15, Suppl. 6, S6-49-S6-55.

22. Yeum KJ, Ahn SH, Rupp de Paiva SA, Lee-Kim YC, Krinsky NI \& Russell RM (1998) Correlation between carotenoid concentrations in serum and normal breast adipose tissue of women with benign breast tumor or breast cancer. J Nutr 128, 1920-1926.

23. Carpenter MA, Crow R, Steffes M, Rock W, Heilbraun J, Evans G, Skelton T, Jensen R \& Sarpong D (2004) Laboratory, reading center, and coordinating center data management methods in the Jackson Heart Study. Am J Med Sci 328, 131-144.

24. Champagne CM, Bogle ML, McGee BB, Yadrick K, Allen HR, Kramer TR, Simpson P, Gossett J \& Weber J (2004) Dietary intake in the lower Mississippi delta region: results from the Foods of our Delta Study. J Am Diet Assoc 104, 199-207.

25. Food and Nutrition Board, Institute of Medicine (2000) Dietary Reference Intakes for Vitamin A, Vitamin $K$, Arsenic, Boron, Chromium, Copper, Iodine, Iron, Manganese, Molybdenum, Nickel, Silicon, Vanadium, and Zinc. Washington, DC: National Academy Press.

26. Ford ES (2000) Variations in serum carotenoid concentrations among United States adults by ethnicity and sex. Ethn Dis 10, 208-217.

27. Jacques PF \& Chylack LT Jr (1991) Epidemiologic evidence of a role for the antioxidant vitamins and carotenoids in cataract prevention. Am J Clin Nutr 53, Suppl. 1, 352S-355S

28. Tucker KL, Chen H, Vogel S, Wilson PW, Schaefer EJ \& Lammi-Keefe CJ (1999) Carotenoid intakes, assessed by dietary questionnaire, are associated with plasma carotenoid concentrations in an elderly population. J Nutr 129, $438-445$

29. Connor SL, Ojeda LS, Sexton G, Weidner G \& Connor WE (2004) Diets lower in folic acid and carotenoids are associated with the coronary disease epidemic in Central and Eastern Europe. J Am Diet Assoc 104, 1793-1799.

30. Tangney CC, Bienias JL, Evans DA \& Morris MC (2004) Reasonable estimates of serum vitamin $\mathrm{E}$, vitamin $\mathrm{C}$, and $\beta$-cryptoxanthin are obtained with a food frequency questionnaire in older black and white adults. J Nutr 134, 927-934.

31. Bermudez OI, Ribaya-Mercado JD, Talegawkar SA \& Tucker KL (2005) Hispanic and non-Hispanic white elders from Massachusetts have different patterns of carotenoid intake and plasma concentrations. J Nutr $\mathbf{1 3 5}$, $1496-1502$.

32. Vogt TM, Mayne ST, Graubard BI et al. (2002) Serum lycopene, other serum carotenoids, and risk of prostate cancer in US Blacks and Whites. Am J Epidemiol 155, 1023-1032.

33. Jacques PF, Sulsky SI, Sadowski JA, Phillips JC, Rush D \& Willett WC (1993) Comparison of micronutrient intake measured by a dietary questionnaire and biochemical indicators of micronutrient status. Am J Clin Nutr 57, 182-189.

34. Willett WC, Stampfer MJ, Underwood BA, Speizer FE, Rosner B \& Hennekens CH (1983) Validation of a dietary questionnaire with plasma carotenoid and $\alpha$-tocopherol levels. Am J Clin Nutr 38, 631-639.

35. Coates RJ, Eley JW, Block G, Gunter EW, Sowell AL, Grossman C \& Greenberg RS (1991) An evaluation of a food frequency questionnaire for assessing dietary intake of specific carotenoids and vitamin E among low-income black women. Am J Epidemiol 134, 658-671.

36. Dixon LB, Subar AF, Wideroff L, Thompson FE, Kahle LL \& Potischman N (2006) Carotenoid and tocopherol estimates from the NCI diet history questionnaire are valid compared with multiple recalls and serum biomarkers. J Nutr 136, 3054-3061.

37. Kabagambe EK, Baylin A, Allan DA, Siles X, Spiegelman D \& Campos H (2001) Application of the method of triads to evaluate the performance of food frequency questionnaires and biomarkers as indicators of long-term dietary intake. Am J Epidemiol 154, 1126-1135.

38. US Department of Agriculture (2005) National Nutrient Database for Standard Reference, Release 18. http://www.ars. usda.gov/Services/docs.htm?docid=9673 (accessed February 2006). 
39. VandenLangenberg GM, Brady WE, Nebeling LC, Block G, Forman M, Bowen PE, Stacewicz-Sapuntzakis M \& MaresPerlman JA (1996) Influence of using different sources of carotenoid data in epidemiologic studies. J Am Diet Assoc 96, 1271-1275.

40. Porrini M \& Riso P (2005) What are typical lycopene intakes? J Nutr 135, 2042S-2045S.

41. Garcia-Closas R, Berenguer A, Jose Tormo M et al. (2004) Dietary sources of vitamin C, vitamin E and specific carotenoids in Spain. BrJ Nutr 91, 1005-1011.
42. Manzi F, Flood V, Webb K \& Mitchell P (2002) The intake of carotenoids in an older Australian population: The Blue Mountains Eye Study. Public Health Nutr 5, 347-352.

43. Nebeling LC, Forman MR, Graubard BI \& Snyder RA (1997) Changes in carotenoid intake in the United States: the 1987 and 1992 National Health Interview Surveys. J Am Diet Assoc 97, 991-996.

44. Clinton SK (1998) Lycopene: chemistry, biology, and implications for human health and disease. Nutr Rev $\mathbf{5 6}$, $35-51$. 